\title{
REMOTE CONTROL GENERAL ANAESTHESIA AND BRONCHOGRAPHIC TECHNIQUE IN INFANTS AND CHILDREN*
}

\author{
Guy Fortin, M.D., ANdré Mackay, M.D., Gilles Lorange, M.D., \\ Hugues Turnier, M.D., aNd ROger Mathleu, PH.D. $\dagger$
}

IN THE PAST, a great variety of anaesthetic procedures, both local and general, have been introduced to meet the requirements of bronchography. The anaesthetist has had to meet the individual exigencies of the medical interhist trained in endoscopy, the otolaryngologist, and sometimes the thoracic surgeon who performs his own diagnostic procedures. Under such circumstances it is not surprising that generally accepted standarized bronchographic and anaesthetic techniques have yet to be established and remain a challenge.

In adults, local anaesthesia is very adequate and acceptable to the patient provided the bronchographic procedure is performed by a skilled specialist. For obvious reasons, bronchography performed under local anaesthesia in children can be and usually is a formidable enterprise. With the possible exception of aerosol nebulization, ${ }^{1}$ local anaesthetic procedures in children are not only difficult to perform but also expose them to toxic reactions. They are usually time consuming and require a great deal of patience. Notwithstanding complete local anaesthesia of the hypopharyngeal region and upper respiratory tract, the. subsequent introduction of the dye into the bronchi can in itself be difficult to perform in children. Methods based on the fact that opaque material will be aspirated into the larynx rather than be swallowed after complete anaesthetization of the hypopharyngeal region, ${ }^{2}$ usually require a large quantity of dye which is introduced via catheter into the nasopharyngeal region and exposes the patient to toxic reactions. The postural methods ${ }^{3}$ subesquently used to distribute the dye by gravity are not always reliable. A bilateral study often cannot be performed in one session. The management of such a procedure proves to be very difficult and exhausting both for the diagnostician and the patient. The taking of films with a squirming, balky, half-drowned child, fighting for breath and who must be forcibly restrained, does not always give excellent results and necessarily exposes the hands of the attendants to a greater radiation hazard.

Techniques conducted under general anaesthesia for bronchography in children are numerous. An excellent review has been presented by Parkhouse ${ }^{4}$ and there is no necessity to elaborate on classical techniques and their variations here. Essentially, these techniques are performed either with or without an endotracheal airway after establishment of anaesthesia, usually with ether.

*Presented at the annual meeting of the Canadian Anzesthetists' Society, Quebec Division, Royal Victoria Hospital, Montreal, P.Q., Feb. 6, 1960, and as an exhibit at the Second World Congress of Anaesthesiologists, Toronto, September 4-10, 1960.

†From the Department of Anaesthesia, the Chest Clinic, and Radiological Physics Laboratory, Notre Dame Hospital, Montreal, P.Q.

Can. Anaes. Soc. J., vol. 8, no. 3, May, 1961. 
When the child is not intubated, the dye is injected by a syringe via a small catheter introduced through the mouth or nose into the trachea. Sometimes in the "drowning technique" as described under local anaesthesia, manipulations are reduced to a minimum and the opaque medium is poured directly into the mouth of the anaesthetized child. These procedures necessarily entail a serious risk to the child patient. In spite of the explosion hazard, moderately deep ether anaesthesia is usually recommended and after initial open ether induction there is no means to control the level of anaesthesia. Excessive amounts of opaque medium are required, sometimes as much as 30 c.c. in larger children. ${ }^{4}$ Under such circumstances it cannot be denied that the child is subjected to a state which is somewhat similar to the process of drowning. Associated local anaesthesia of the upper respiratory tract does not sufficiently protect from bronchospasm. Respiratory obstruction and bouts of cyanosis are bound to occur too frequently. It follows that uncontrolled blind flooding of the bronchial system under general anaesthesia in a child who is not intubated necessitates frantic rapid manœuvres to obtain X-ray records in order to initiate resuscitation without undue delay. Such a procedure is not conducive to consistent good results and the upper lobes often present incomplete filling. Here again the anaesthetist is very likely to expose his hands to the primary beam of the $\mathrm{X}$-rays while attempting to maintain a clear airway in his patient.

When bronchography is performed with the help of endotracheal intubation involving no special modification of anaesthetic instrumentation, the radioopaque material may be injected into the bronchi from a syringe directly into the endotracheal tube or through a small catheter directed into the lumen of the endotracheal tube. The dye may also be injected through a small catheter, which either lies freely alongside the endotracheal tube, or is incorporated into the artificial airway. Here the first two methods necessitate interruption of anaesthesia while the injection procedure is carried out with the patient breathing spontaneously. No interruption of anaesthesia and oxygenation to the patient need occur in the last two methods and relaxant drugs may be used with controlled respiration throughout by means of a closed or non-rebreathing anaesthetic circuit. Although this category of techniques allows for better oxygenation and anaesthetic management, the injection of dye still remains an uncontrolled flooding procedure. The assistance of fluoroscopy does not appreciably compensate for deficiencies in anaesthetic and bronchographic techniques. With a free catheter, depending upon which technique is being used, its manipulation may be either difficult or time limited. An integrated endotracheal tube-catheter system does not lend itself to meticulous work. When a relaxant drug is not used, coughing may cause undesirable obliteration of bronchial detail by blowing dye into the alveoli. The anaesthetist's hands are still dangerously close to the direct $\mathrm{X}$-ray beam and the explosion hazard is ever present should ether be used as the anaesthetic agent of choice.

Amongst the more recent methods, Smith ${ }^{5}$ recommends the use of a $\mathrm{Y}$-adapter attached to the endotracheal tube. One arm of the adapter is fitted with a perforated nipple through which a plastic catheter is passed for insertion of the opaque material. The other arm of the Y-adapter is connected to either a non- 
rebreathing or circle system. In spite of the explosion hazard ether is used to avoid the risk of respiratory depression. Topical anaesthesia of the cords and trachea is associated. Ventilation is assisted or controlled during the procedure but apparently relaxant drugs are not used. The closed anaesthetic circuit is cumbersome for such a procedure in children. The non-rebreathing technique with either an Ayre's T-tube or a manually operated Stephen-Slater or Leigh valve dangerously exposes the anaesthetist's hands to radiation during assisted or 1 controlled respiration. Bowering ${ }^{6}$ presents a very similar procedure, but here a non-explosive type of anaesthesia with a relaxant drug is recommended. Respirations are controlled throughout the procedure. The anaesthetist actually participates in the bronchographic phase by causing the medium to be evenly spread under the influence of deep controlled respirations. It is claimed that the amount of medium used is minimized. The presentation is somewhat lacking in detail and precautions against the radiation hazard seem to be of little concern.

From the foregoing it becomes apparent that successful bronchography under general anaesthesia in children depends on a number of factors.

Improved anaesthesia for bronchography will necessarily result in better performance for the endoscopist and refinements in bronchographic technique will also contribute to better anaesthesia. Oversimplified anaesthetic techniques requiring a minimum of instrumentation do not sufficiently protect the patient nor do they provide adequate conditions to the endoscopist which are necessary to avoid a veritable drowning episode. This implies that the endoscopist should be provided with conditions that will allow him to perform his work meticulously and to limit the quantity of dye injected to a minimum in order to avoid respiratory obstruction and alveolar filling. Since coughing causes alveolar filling which contributes to cyanosis and also interferes with interpretation of X-ray records, the cough reflex must be completely eliminated by appropriate means. Since bronchography under fluoroscopic control must be carried out in total darkness, the endoscopist and anaesthetist must work in uncluttered surroundings. The anaesthetist must give his undivided attention to his patient and should eliminate from his technique unnecessary distracting manœuvres. Groping in the dark for instruments, drugs, and so on must be avoided. For these reasons, anaesthetic instrumentation must be designed in such a manner that will provide immediately available finger-tip controls, easily accessible for manipulation in the dark. Flowmeters on anaesthetic machines should be-provided with luminous dials visible in the dark. The Boyle anaesthetic machine is so equipped. Under such working conditions, however, a subdued light source should be immediately available to the anaesthetist for intermittent observation of the child's colour.

Notwithstanding the overwhelming recommendations with regard to ether as the choice of anaesthetic agent for bronchography in children, we firmly believe that an explosive agent should not be used in the immediate vicinity of an $\mathrm{X}$-ray machine. There are enough problems involved in this anaesthetic procedure without having to cope with the explosion hazard. Non-explosive anaesthetic agents associated with a relaxant drug can provide a well-controlled superficial degree of narcosis and a fast return of natural defense mechanisms after the procedure. 
With improved bronchographic and anaesthetic techniques, the advantages of diagnostic bronchography can be extended to younger children and infants. This means that the endoscopist and anaesthetist will be called upon more often to perform this procedure and hence will be faced with the problem of repeated exposure to radiation. ${ }^{7}$ Therefore not only should usual precautions be observed, such as the wearing of a leaded apron by all those attending the procedure, but also innovations should be incorporated in the anaesthetic technique so as to either nullify or at least diminish the radiation hazard to the unprotedted hands. Herein lies the advantage of remote control anaesthesia whereby the hands of the anaesthetist need not be exposed to the useful $\mathrm{X}$-ray beam. Added to these considerations is the fact that the more precise a bronchographic procedure becomes, the longer the performance time and hence the greater the radiation hazard.

In bronchography it is essential that precautions against the radiation hazard be observed as recommended for any other procedure involving fluoroscopy, and set forth in Handbook 60 of the National Bureau of Standards. ${ }^{8}$ When unmodified techniques of general anaesthesia for bronchography in infants and children are used, our observations reveal that regardless of an honest attempt to apply fundamental safety precautions, the radiation hazard to the endoscopist and anaesthetist is' greater than in other procedures where there is no necessity for the hands of the operators to be in close proximity to the useful $\mathrm{X}$-ray beam. As a general rule, the hands, either bared or gloved, should never encroach upon the direct path of the useful X-ray beam unless the beam is attenuated by the patient. In bronchography the wearing of gloves by the endoscopist and anaesthetist greatly hamper manipulations and they must proceed $_{n}$ with their bared hands. By restricting the field size to a minimum, a skilled radiologist can safeguard the hands of his colleagues from the useful X-ray beam during fluoroscopy. Spot filming and the recording of standard size films, however, necessitate a wider beam which infringes on a greater area than the fluoroscopic control beam. This introduces another hazard to the hands of the operators which is difficult to control but which nevertheless should not be ignored.

When the hands are held at a distance of 18 inches from the periphery of the $\mathrm{X}$-ray beam, they receive from five to ten times less radiation in relation to the maximum scattered dose. By increasing this distance one foot more, scattered radiation decreases by a negligible factor of 1.5 to 2 . We therefore recommend as a safety precaution that the hands of the operators during bronchography be kept at a distance of not less than one and one-half feet from the periphery of the $\mathrm{X}$-ray beam covering the widest field.

The technique developed by us was arrived at by joint consideration of all the problems involved. Requirements for the safety of the patient have always'been foremost in our considerations and we have attempted to fulfill as well as possible all other requirements previously discussed.

The principle involving the injection of dye by means of a catheter passed through the endotracheal tube without interfering with the simultaneous maintenance of general anaesthesia and artificial respiration is attributed to Baker and has been adapted to our technique. In Baker's method of bronchography in 
children under general anaesthesia, the catheter is not inserted beyond the bifurcation of the trachea and the injected dye is dropped in either bronchus by gravity through suitable posturing of the patient. Ether is used and no special precaution to reduce the radiation hazard is recommended. Although the principle of this method was introduced in 1941, it is surprising to find that so many attempts have since been made at more simple procedures which have ignored the basic and logical technical recommendations set forth by Baker. The objection has been raised that a catheter inserted into the narrow lumen of a small endotracheal tube, such as is used in infants, restricts the airway and causes partial obstruction. ${ }^{10}$ For this reason, we find that the use of an endotracheal tube in infants and children is excluded from many techniques. The contention is certainly justified when a large quantity of radio-opaque medium is used, which by/itself can cause severe mechanical obstruction. We are convinced, however, that a capillary polyethylene catheter small enough to allow free ventilation between its wall and that of the endotracheal tube can always be found, however small the lumen of the endotracheal tube. A thin-walled endotracheal tube should be used. The quantity of dye injected should be restricted to a minimum compatible with the size of the patient. This will eliminate a source of gross respiratory obstruction and will not interfere with results. Intermittent positive pressure ventilation is also an important compensatory factor for the resistance which may result from the introduction of a small catheter into the lumen of the endotracheal tube. It may be argued that free injection of an opaque substance through a capillary-sized catheter is impossible. The same law applies to small bore catheters as it does for small needles ${ }^{11}$ so that it is always possible to inject the medium by using a small capacity syringe which provides a greater mechanical advantage. Preheating of the contrast medium reduces viscosity and facilitates injection.

The self-contained anaesthetic apparatus is illustrated in Figure 1. It consists of a non-rebreathing, semi-automatic Fink valve ${ }^{12}$ mounted on a metallic extension tube 18 in. long. An oral right-angled Adams' connector provided with a suction orifice is mounted on the distal extremity of the valve. The uncapped suction orifice is fitted with a short length of rubber tubing $1 \frac{3}{4}$ in. long. This tube is inserted through a tight-fitting circular aperture in a specially designed clamping device provided with a dual kinking and constricting action. This clamp mechanism is relayed to a thumb lactivated remote-control lever by a Bowden cable. The proximal extremity of the tubular extension is mounted with a reservoir bag designed by Ruben. ${ }^{13}$ The Ruben bag is a self-inflating device fitted with an air intake valve. It has been modified to administer an anaesthetic mixture by incorporating a perforated plastic chamber on the air intake valve. This perforated chamber bears a nipple which receives a delivery tube from the anaesthetic machine. Thus gases are delivered to the bag during the expansion phase only and excess flow escapes to the atmosphere, by the application of Ayre's insufflation principle ${ }^{14}$ in order to avoid pressure build-up from this source. The Ruben bag is manufactured in two models. One model is provided with an oxygen inlet nipple incorporating a check valve. This inlet nipple presents a pressure build-up hazard in our apparatus when used for the delivery of gases. 


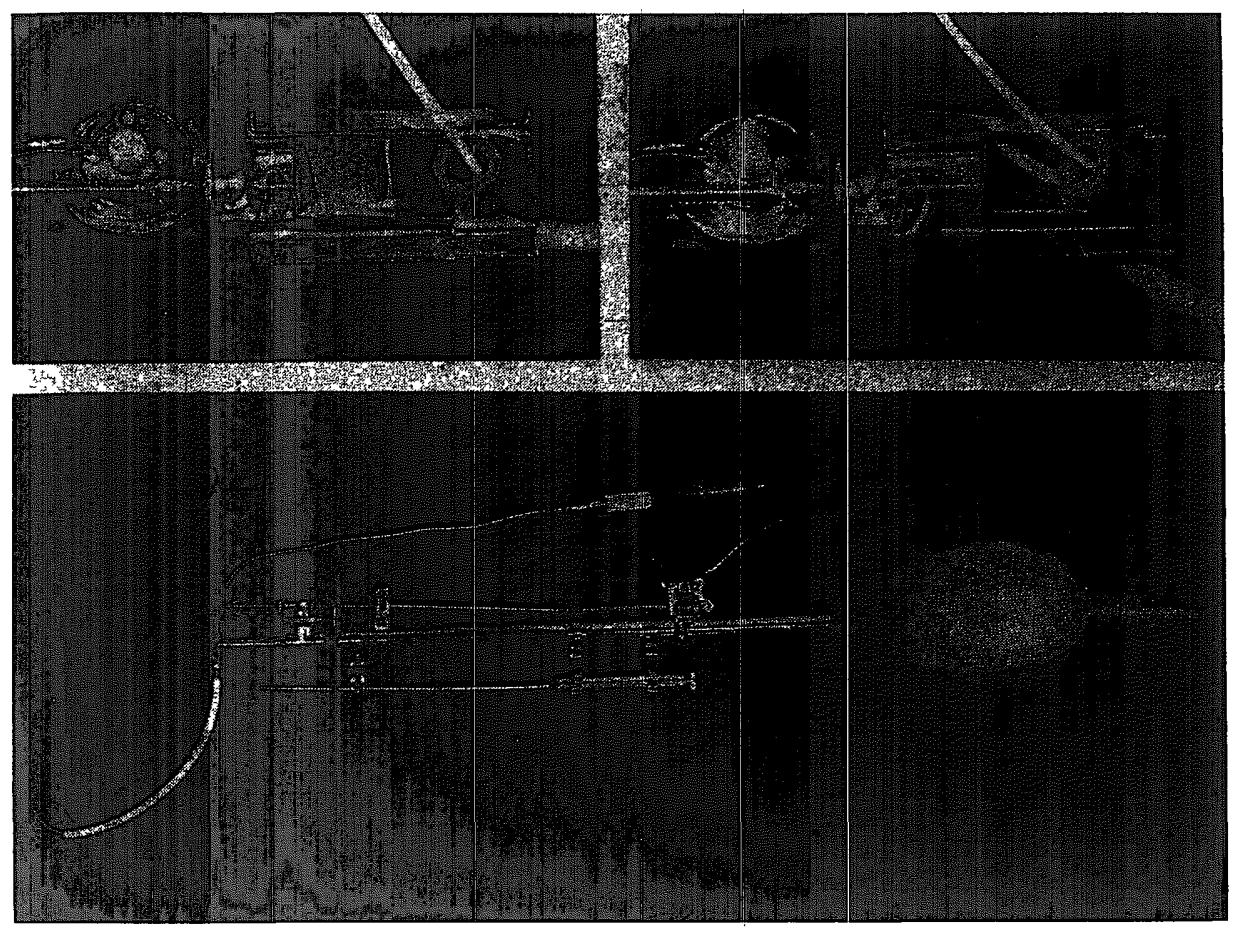

FIGURE 1. Remote control anaesthesia apparatus for bronchography showing injecting catheter connected to $10 \mathrm{cc}$. syringe and passing through endotracheal tube Left insert shows clamp mechanism operated by remote control in the open position Right insert shows clamp in the closed position (see text for description).

We recommend the model which is manufactured without an oxygen intake nipple and modified according to our specifications for gas intake. A flashlight extension powered by a pen-type battery is mounted as shown on the long tube. This immediately available light source is intended for intermittent observation of the patient's colour and can be turned on and off at the proximal end of the tube.

In use, the pressure release valve on the Fink valve is kept closed at all times. Depression of the thumb lever causes the rubber tubing, through which various size catheters may be introduced, to be sealed hermetically around the catheter by the clamp, thus allowing the anaesthetist to control respirations. The clamp is momentarily released to allow the endoscopist to insert and properly locate the catheter inside the bronchus. The clamp must also be momentarily released during injection of the opaque material. To deliver the anaesthetic mixture to the patient or to administer oxygen, the clamp is closed and controlled respiration is performed by manual intermittent pressure on the Ruben bag. As mentioned before, pressure build-up cannot possibly result from a high flow of gases, although the pressure release on the Fink valve is kept closed. 
The Ruben bag is an indispensable part of the apparatus since it releases the anaesthetist from the obligation of periodic adjustment of gas flows following initial setting to meet the variable volumetric ventilatory demands of the patient. Should gas delivery be insufficient to completely occupy the volume of the selfinflating bag, air dilution will occur through the air-intake valve in the bag. Excessive air dilution can be prevented by limiting the rate of inflation of the bag with the hand. Thus the anaesthetist is free to give his undivided attention to his patient, an essential part of the procedure. All that is required of him is an occasional glance at the luminous flowmeter dial to ascertain that gas flow settings have not been accidentally disturbed.

The tubular extension of the apparatus is intended as a safeguard against the radiation hazard. Unmodified anaesthetic apparatus necessarily exposes the anaesthetist to this danger. This is particularly true in infants and small children where the lower part of the head almost encroaches upon the useful beam of the $\mathrm{X}$-rays. With a standard manual non-rebreathing technique, the anaesthetist's hands necessarily come dangerously close to the beam should controlled respiration be required. This manœuvre entails simultaneous manual obstruction of the expiratory valve with each compression of the reservoir bag. In the closed circuit technique, the drag of the cumbersome breathing tubes must be supported at a point close to the endotracheal tube to prevent accidental extubation.

The entire apparatus may be quickly and completely dismantled for cleaning and sterilizing. This necessary procedure is extremely important in infected cases.

Prior to the bronchographic procedure, postural drainage is carried out if excessive secretions are present. When the patient is ready, a fairly heavy premedication compatible with age, weight, and general condition is given. Should the child not be sufficiently sedated when he arrives for his diagnostic procedure, we refrain from aggressive induction of anaesthesia and supplement the premediation with rectal pentothal. A short 22- or 23-gauge needle is installed intravenously either in the arm or the foot and an isotonic glucose solution is administered from a bottle containing a small quantity of fluid to avoid accidental cardiovascular overload. The needle is never inserted under duress and if necessary it is inserted after induction of light fluothane narcosis by the non-rebreathing technique. A small bore intravenous extension set with a readily accessible injection site is installed for the administration of drugs during the procedure.

If necessary, prior to the bronchography, bronchoscopy is carried out under general anaesthesia. The same precautions as recommended for bronchography are observed during this preliminary procedure.

Endotracheal intubation is performed after induction with fluothane or a small dose of pentothal intravenously followed by an appropriate dose of succinylcholine.

Local spray of the vocal cords and trachea can be a hazard in children and it is best to avoid it if at all possible. On standing, local anaesthetics for topical anaesthesia have the property of crystallizing out of solution as a result of evaporation of the solvent and the crystals accumulate along the distal end of the atomizer extension tube and around the nozzle. The solution which remains in the tube may become highly concentrated also through evaporation of the 
solvent. One single spray from such an atomizer which has been standing overnight or longer after previous use can vehicle not only a strongly concentrated solution but also undissolved crystals of the anaesthetic agent. In children the best precaution is to limit topical anaesthesia of the vocal cords and trachea to a lubricating anaesthetic jelly applied to the endotracheal tube.

Following intubation, tracheal and bronchial suction is carried out by the anaesthetist if necessary by means of a small suction catheter passed through the endotracheal tube. The endotracheal tube is then connected to the remote control apparatus and anaesthesia is maintained by a non-explosive mixture of oxygen, nitrous oxide, and fluothane: For this combined insufflation and inhalation non-rebreathing technique, the total flow of gases is set at around $8 \mathrm{~L}$. per minute and the oxygen concentration is established at 40 per cent or higher.

Control of the cough reflex is obtained by complete curarization either with a continuous intravenous succinylcholine drip or by intermittent administration of the relaxant drug.

Controlled respiration is carried out by compression of the Ruben bag with the clamp closed around the catheter inlet tube. As explained previously, should air dilution occur during controlled respiration, the potency of fluothane is such that this will not appreciably disturb the degree of narcosis. Owing to smaller volumetric ventilatory requirements, air dilution is less likely to occur in infants and children than in adult patients. Moreover, deep anaesthesia is not required when a relaxant drug is used. The clamp is now released momentarily to allow the endoscopist to introduce a polyethylene catheter of appropriate size, previously filled with pre-heated opaque medium, into the endotracheal tube.

The endobronchial opacification technique in infants and children derives from the adaptation of principles which govern a method for preliminary selective segmental bronchography, usually performed under local anaestheșia in adults. This method was recently described by one of us (A. M.) and includes a report of 335 cases. $^{15}$

Preliminary isolated segmental bronchography in adults is achieved by the use of endobronchial injecting catheters specially designed for this purpose by $M^{2} \operatorname{tras}^{16}$ in 1947. Under fluoroscopic control, Metras catheters of proper size and possessing appropriate molded tips are alternately inserted into the corresponding lung, lobe, and segment. Should the radiologist observe segmental pathology while the opacification procedure is in progress, extemporaneous records are made on spot films after which the bronchogram is completed and standard postero-anterior lateral and oblique films are recorded. This procedure applies in reverse a bronchographic technique described by Nordenström ${ }^{17}$ whereby diffuse bronchial instillation is initially attempted after which the segments not injected are filled selectively. The extemporaneous recording of what appears to be segmental pathology under fluoroscopic observation presents a definite advantage. Loss of detail which may otherwise result from subsequent bronchial emptying is thereby avoided.

Although Metras catheters of small calibre are not available at present, the foregoing meticulous preliminary selective procedure may be attempted under general anaesthesia in infants and children by the substitution of polyethylene 


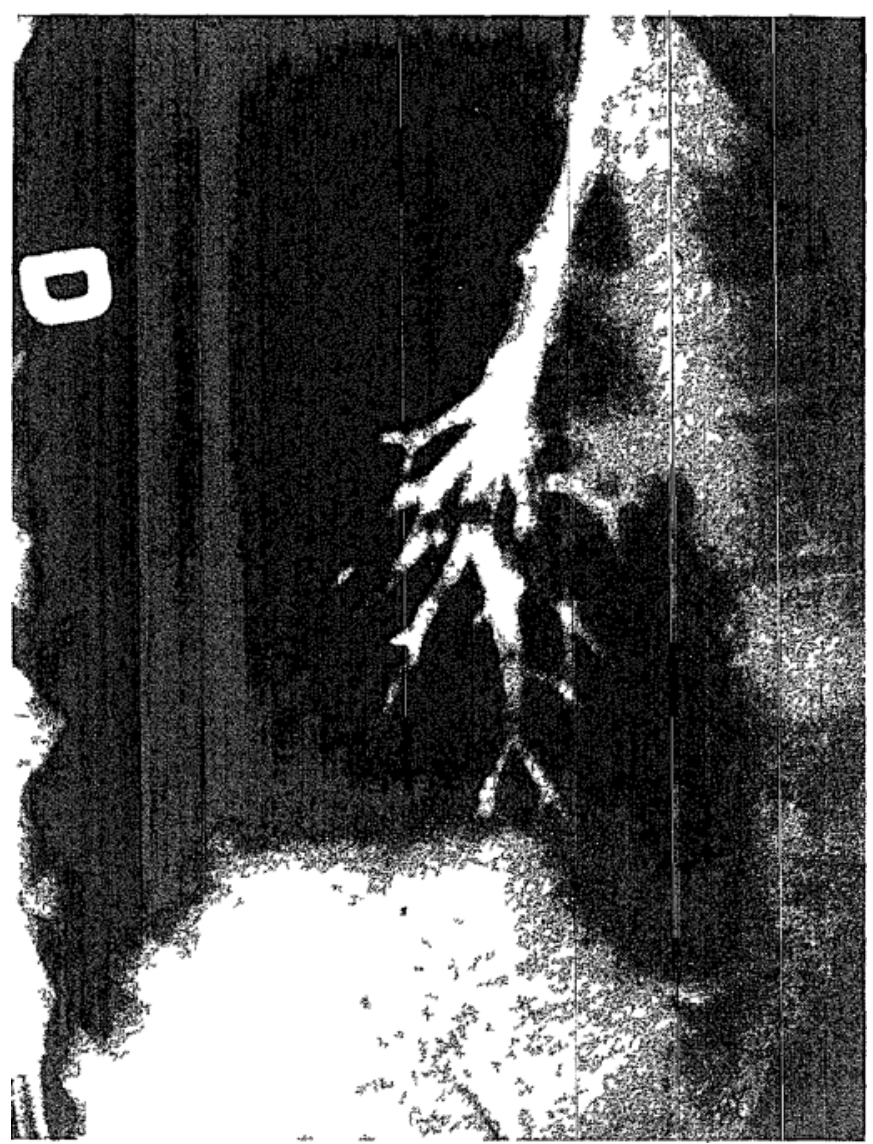

Figure 2 This right lower lobe bronchogram of a six year-old child obtaned under general anaesthesia sllustrates possibility of preliminary selective lobar bronchography in children

capillary tubing for the Metras catheters Obviously with these improvised injecting catheters, preliminary isolated segmental selectivity cannot be obtained in infants and children Prelimınary selective opacification of lobar dimension, however, may be obtaned (Figs 2 and 3 ) Under fluoroscopic control, the endo scopist Jocalizes the polyethylene tubing, previously opacified by fillng with radıo-opaque medium at the level of the suspected segmental pathology Perfect co ordination and tıming must prevall between endoscopist and radiologist who must not be distracted by having to worry over the condition of the patient Manipulation of the catheter must be carried out blindly while its position is checked by intermittent fluoroscopic observations of short duration during which time the endoscopist must remove his hands from the direct $\mathrm{X}$ ray beam In order to provide adequate protection to the endoscopist from the radiation 


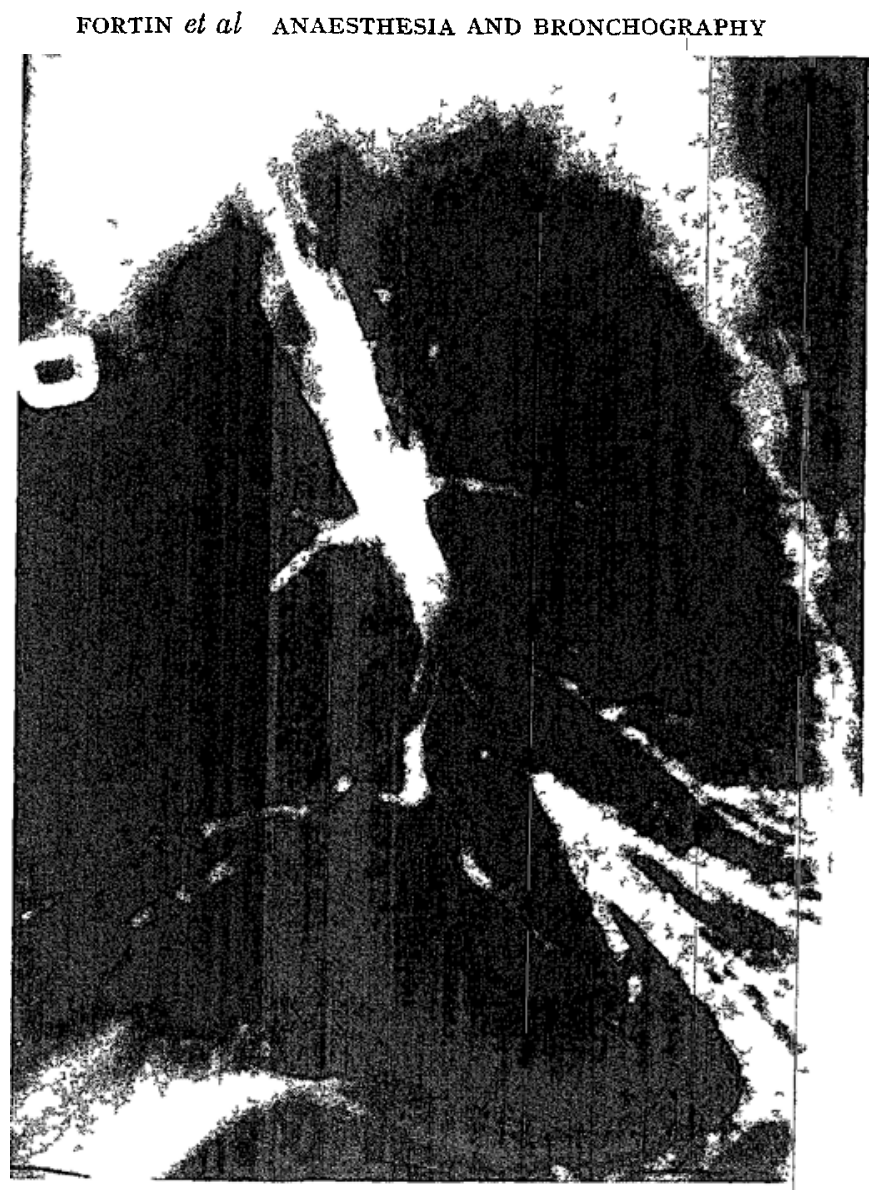

Figure 3 Same patient as in Figure 2 showing completed right bronchogram in the lateral position

hazard, the injecting catheter should be at least two feet long Whenever necessary, the anaesthetıst ventılates the patient by closure of the clamp on the remote control anaesthetic extension and the condition of the patient is checked by momentarly flashing on the extension light Advantage is taken of the intermittent fluoroscopic images to check on cardiac action and the effectiveness of artificial ventilation When the catheter has been properly placed, the endoscopist proceeds to a controlled injection of a discrete quantity of radio-opaque medium The amount of dye required for adequate double contrast pictures is determined by the radiologist Simultaneously, the anaesthetıst applies gentle positive pressure by intermittent compression of the Ruben bag At this particular time, partial closure of the remote control clamp without causing constriction of the injecting catheter will not interfere with either the injection procedure or the control of respiration Thus under fluoroscopic and ventilatory control the 


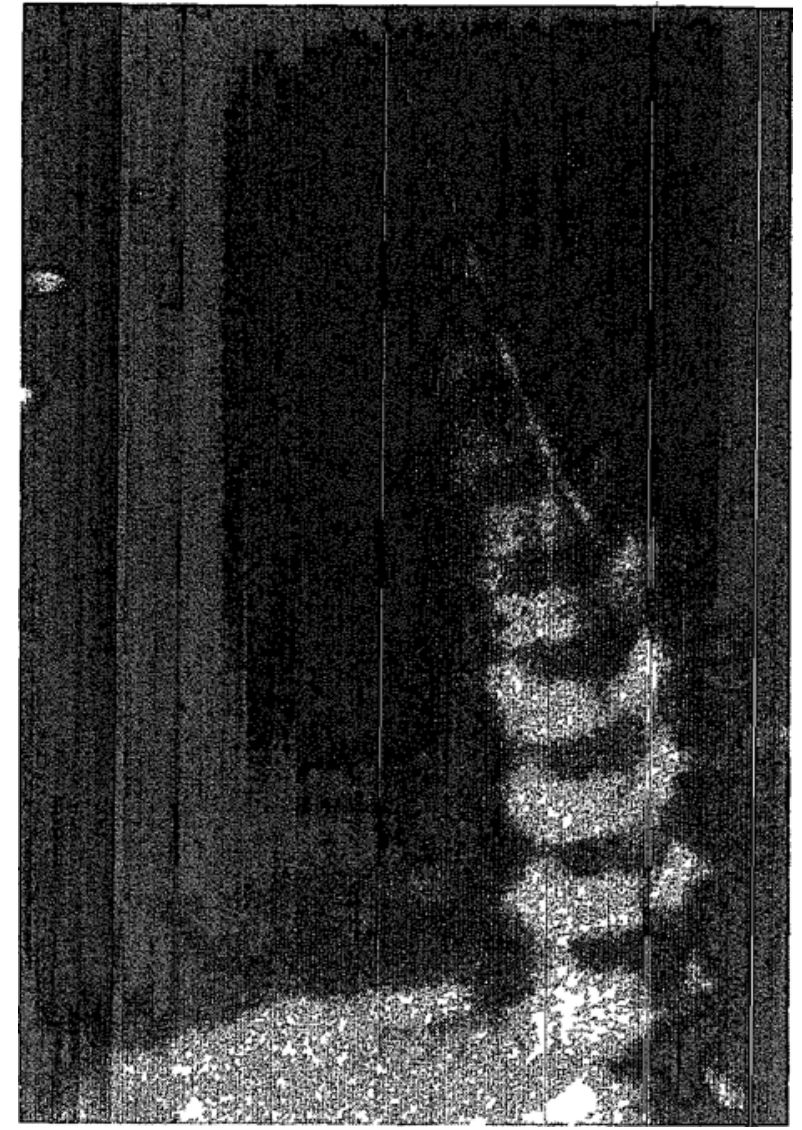

Figure 4 Spot film illustrates position of opacified plastic injectung catheter in the left man bronchus of a fourteen day old infant Note small size catheter (no $5 \mathrm{Fr}$ ) Endotracheal tube (no 0 Magill scale) may be discerned in the trachea and it may be seen that its lumen is not grossly reduced by the presence of the small muectning cathet ${ }^{2}$

minimum quantity of radio opaque medium required to coat the bronchi under observation is evenly spread into the lung segments which are opposite the site of the catheter tip ${ }^{6}$ Under complete apnoea, spot films are made the moment pathology is detected and also following complete filling of the lobe under observation Taking advantage of the natural curvature of the plastic catheter, the tip is again oriented towards another lobe and the same procedure is again repeated After complete opacification of the bronchial arborization of the lung under exammation, standard films are made of the completely immobilized lung

After the procedure, following return of adequate spontaneous respiratory activity, the X-ray table is tilted in the head-down position to accomplish gravity 


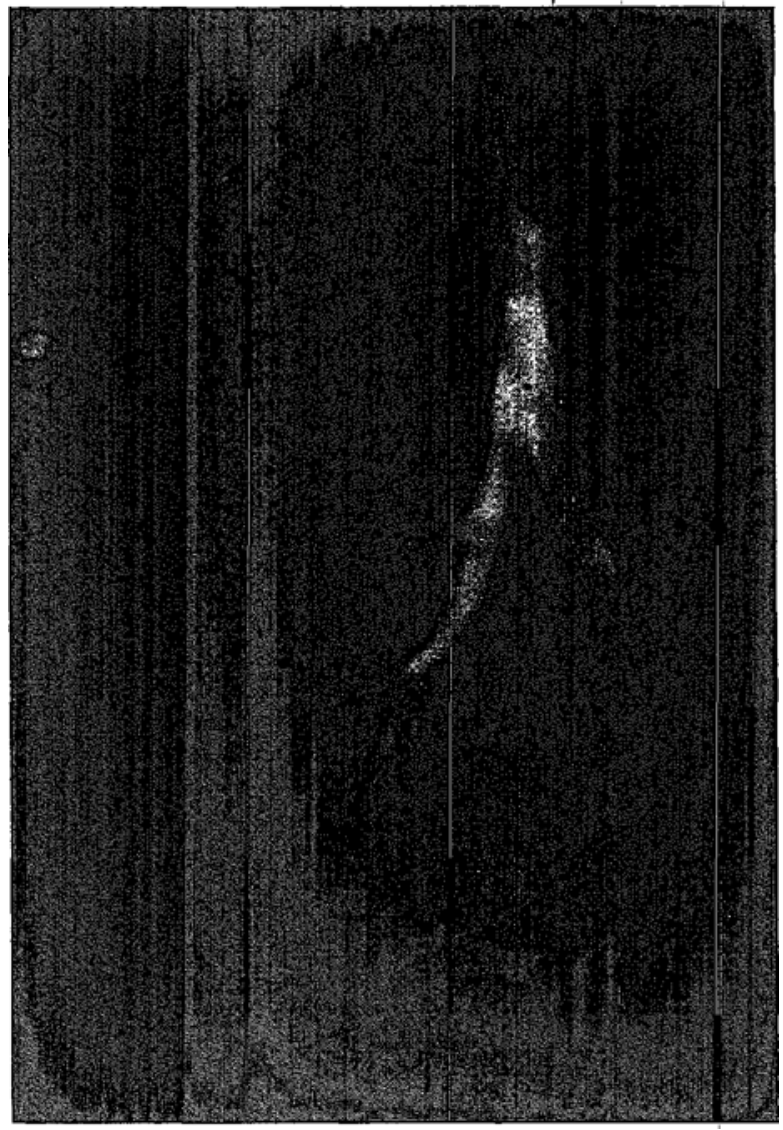

FIGURE 5. Same patient as in Figure 4. Right bronçhogram/showing Dionosyl in right main bronchus and demonstrating patency of the roots of the segmental bronchi Note injecting catheter in right main bronchus. Here intentional forceful injection of Dionosyl has caused some spilling of the opaque medium into the left main bronchus.

drainage and the lung examined is suctioned out by means of a catheter passed through the endotracheal tube. In a bilateral examination, the first lung injected is cleared of excess dye before proceeding with the opacification of the second lung. Following aspiration of the oral cavity, the endotracheal tube is removed after complete return of natural defence mechanisms, and oxygen is administered by mask. The patient is kept under close observation until fully awake. After a bronchographic procedure preceded by a bronchoscopic examination, the child is placed in a high humidity tent, if necessary, until all signs of laryngeal irritation have disappeared.

The radio-opaque medium which we use for bronchography is a chemically 
stable, non-oily iodine preparation in an aqueous suspension known under the trade name of Dionosyl ${ }^{\oplus}$. Its properties have been presented elsewhere ${ }^{18}$ and need not be discussed at length here. Amongst its outstanding qualities, Dionosyl has no tendency to produce alveolar filling. Controlled respiration will not blow this contrast agent into the alveoli, provided it is used properly under conditions which will allow controlled minimum bronchial injection. This property is due to the fact that Dionosyl spreads evenly and adheres readily to bronchial mucosa. The lumen of the bronchi need not be flooded to procure uniform opacification. Thus a limited amount of dye is required and the resulting record presents a more natural appearance. Excretion does not involve the breakdown of Dionosyl to free iodine or inorganic iodide and for this reason it is said that Dionosyl is practically non-toxic. When used in minimum amounts, compatible with good results, Dionosyl is usually absorbed from the lungs within 48 hours.

Using the method described, we have performed to date a total of 40 bronchographies in infants and children under general anaesthesia. Unilateral bronchographies were performed on seven patients and bilateral procedures on 33 patients. The infant group included 14 cases ranging in age from two weeks to two years and an average age of 18.75 months. The child group included 26 patients ranging in age from three to nine years and an average age of 5.15 years. In the infant age group, the average quantity of Dionosyl used to opacify a single lung was 4.5 c.c. In the child age group, the average volume of Dionosyl required to opacify a single lung was 5.2 c.c.

Figures 4 and 5 illustrate technique and diagnostic results in a 14-day-old infant. Bronchography in this very young, transfused, ery throblastotic patient was indicated to rule out the possibility of bronchial agenesis or atresia on the side of a collapsed lung. Immediately following bronchography, a left endobronchial intubation was done under fluoroscopic control and a right thoracotomy was performed. Encysted empyema cavities were drained and the right lung was decorticated. The right consolidated atelectatic lung gradually re-expanded and the infant was discharged from the hospital in a good state of health one month after operation. This case illustrates that bronchographic procedures need not be withheld from the very young, so that they may benefit from life-saving surgical measures applied without undue delay.

\section{Discussion}

Although our method of general anaesthesia for bronchography in infants and children -may appear to be complicated and to involve lengthy recommendations, the precautions herein sett forth also apply to all methods of bronchography under general anaesthesia, however simple the technique may be. Indeed, oversimplification of technique, by reducing anaesthetic equipment to a minimum, deprives the patient of safety measures against a procedure which involves a serious risk. Whenever possible, a diagnostic procedure should not entail a greater risk to the patient than the subsequent therapeutic measure.

Although our anaesthetic apparatus is largely made up of standard anaesthetic 
accessories, it could lead to a certain degree of carbon dioxide accumulation and anoxia in infants in the hands of the unwary. This would occur as a result of turbulence and rebreathing between the space separating the inspiratory valve on the Fink valve and the distal extremity of the Adams' connector. In spite of the oversize anaesthetic accessories, carbon dioxide-accumulation and anoxia need not occur. The gases at the distal end of the apparatus are washed out and replaced periodically by opening the remote control clamp while simultaneously compressing the bag.

The entire apparatus could be made to handle more conveniently by incorporating plastic components throughout or by the use of lighter alloys. With the patient's head turned to one side, however, the apparatus need not be supported by the anaesthetist. It is made to rest conveniently on the $\mathrm{X}$-ray table.

Since spontaneous breathing entails the opening of two inspiratory valves (one on the Ruben bag, the other on the Fink valve), respirations should always be controlled in infants and young children to avoid fatigue in the patients.

It is sometimes advisable, in bad risk cases involving extensive lung pathology, that the anaesthetic duties be shared by two anaesthetists. While one anaesthetist attends to parenteral requirements, the other gives his undivided attention to the inhalation procedure. In this way, less fumbling is likely to occur while working in the dark. Bronchography under general anaesthesia in older children and adults is performed with the same anaesthetic apparatus but here the special Metras catheters are used.

In the early stages of our experience with this method, we have witnessed the occurrence of spontaneous segmental atelectasis on two occasions during the fluoroscopic procedure. Presumably, these atelectatic areas were caused either by the injection of excessive amounts of Dionosyl with resultant segmental obstruction or by oversized injecting catheters which restricted alveolar ventilation. Smaller quantities of Dionosyl and greater precaution in the selection of injecting catheters of proper size have eliminated this complication.

In children, we have found that the Baxter plexitron administration set no. R33 very useful when used as a catheter to inject the Dionosyl. The needle adapter of the R33 is cut off and the Luer-type connecting tube at the other extremity is used for attaching the syringe containing the Dionosyl. Although somewhat soft, the tube may be guided fairly easily into either bronchus provided it is well lubricated with a water-soluble jelly. The smallest endotracheal tube that will accommodate this improvised catheter without causing serous mechanical obstruction is a no. 3 (Magill scale) plastic tube. For smaller endotracheal tubes, ranging in diameter from 0 to 2 (Magill scale), a no. 5 (Fr. scale) plastic infant feeding tube is used. Until a proper relative scale for endotracheal tube and corresponding catheter has been established, we recommend that the selection of injecting catheters be carried out extemporaneously on a trial and error basis before proceeding with the bronchography. A catheter which grossly obstructs the lumen of the endotracheal tube and interferes with ventilation, either spontaneous or controlled, should be rejected and replaced by another of smaller gauge. 


\section{SUMMARY}

A brief review of the principles involved in various methods of bronchography for infants and children under local and general anaesthesia is presented. The dangers involved and technical difficulties of performing bronchography without an endotracheal tube are discussed. Current methods of bronchography which include endotracheal intubation as part of the procedure are described and analysed.

The requirements for the performance of successful bronchography are stated. It is pointed out that oversimplification of anaesthetic technique exposes the patient to a dangerous hazard and leads to poor results. The use of explosive anaesthetic agents such as ether in the vicinity of an X-ray machine is considered a dangerous practice.

The radiation hazard during bronchography under general anaesthesia is discussed and a special anaesthetic apparatus with remote controls providing protection for the hands of the anaesthetist from the direct X-ray beam is described.

Details concerning the combined inhalation (non-rebreathing) and insufflation anaesthetic techniques involved are given. The principle of a common working airway shared by the anaesthetist and the endoscopist is adapted to the technique.

Recommendations pertaining to pre-anaesthetic preparation of the patient are given.

Induction of anaesthesia in the child is never attempted under duress. The danger involved in spraying the upper respiratory tract with a local anaesthetic agent in infants and children is stressed.

Maintenance of anaesthesia is accomplished with a non-explosive mixture of fluothane, nitrous oxide, and oxygen. Since coughing causes alveolar filling with the contrast agent, the patient is completely curarized to avoid a source of anoxia and obliteration of bronchial detail. Controlled respiration throughout the procedure is an essential part of the preliminary selective bronchographic technique described.

Dionosyl is the contrast medium selected. This dye produces a uniform coating and clings to the bronchial mucosa. There is no necessity to flood the bronchial lumen to obtain radiological results of good quality. When properly used, in limited amounts, controlled respiration will not cause Dionosyl to be blown into the alveoli.

Recommendations pertaining to the immediate post-anaesthetic care of the patient are given.

A report on a clinical study is included.

\section{ACKNOWLEDGMENTS}

We are grateful to Mr. James Sharkay, Consultant Inhalation Therapist, for his valuable technical advice and to Mr. Gaston Royal, Technician, Engineering Department, Notre Dame Hospital, for his assistance in the design and construction of the remote control clamp herein described.*

*The remote-control clamp herein described is not commercially available. 


\section{RÉSUMÉ}

Une revue succincte des principes qui se rattachent aux méthodes diverses de bronchographie sous anesthésie locale et générale chez les enfants est présentée. Les dangers et les difficultés d'ordre technique qui se présentent au cours de la bronchographie pratiquée sans intubation endotrachéale sont mentionnés. Les méthodes courantes préconisant l'usage d'un tube endotrachéal sónt discutées.

Les conditions requisent s'appliquant à la conduite à tenir au cours de la bronchographie sont énoncées.

Le lecteur est mis en garde contre les techniques anesthésiques trop rudimentaires. Celles-ci peuvent être la cause déterminante non seulement d'un échec au point de vue résultat diagnostique mais, ce qui est plus sérieux, d'un accident grave chez l'enfant. L'utilisation de substances anesthésiques explosives, tel l'éther à la salle des rayons-x est une pratique dangereuse.

Il est essentiel de se prémunir contre les dangers d'irradiation au cours de la bronchographie sous anesthésie générale. C'est ce qui motive l'utilisation d'un appareil d'anesthésie à télécommande. Cet appareil apporte à l'anesthésiste un moyen de protection contre les faisceaux directs des rayons-x en lui permettant de tenir ses mains à l'écart.

La technique d'anesthésie préconisée associe l'inhalation et l'insufflation. Le principe d'une voie aérienne artificielle commune, partagée par l'endoscopiste et l'anesthésiste est adapté à la technique décrite.

Quelques conseils concernant la préparation pré-anesthésique $\mid$ du patient sont présentés.

L'induction de l'anesthésie chez l'enfant se fait toujours sans brusquerie. La vaporisation d'un agent anesthésique local au niveau des voies respiratoires supěrieures est déconseillée, en raison du danger de réaction de surdosage.

La phase d'état de l'anesthésie est entretenue avec un mélange non explosif de fluothane, protoxide d'azote et oxygène. Puisque la toux contribue à l'inondation alvéolaire par l'agent de contrast, le patient est curarisé afin d'éviter non seulement le remplissage alvéolaire, source d'anoxie dangereuse, mais aussi, des résultats radiologiques inadéquats. La respiration est contrôlée pendant toute la durée de la procédure. Elle contribue à la technique de bronchographie sélective préliminaire décrite.

Le dionosy ${ }^{\circledR}$ est la substance de contraste de choix. Cet agent semble avoir une affinité particulière pour la muqueuse bronchique et s'étale uniformément pour donner des résultats radiologiques satisfaisants, sans qu'il soit nécessaire d'inonder la lumière bronchique. Utilisé discrètement, tout en respectant les recommandations énoncées, le dionosyl ${ }^{\circledR}$ ne se propage pas jusqu'au alvéoles sous l'influence de la respiration contrôlée.

Les auteurs font quelques recommandations concernant les soins postanesthésiques immédiats et font le releve d'une étude clinique.

\section{REFERENCES}

1. Miller, J. B., Mann, F., \& Abramson, H. A. A method for Topical Anesthesia by Nebulization of Local Anesthetics. Dis of Chest 16: 408-419 (1949). 
2. Nather, K., \& Sgalitzer, M. Zur Technik der Bronchographie ("Verschluck-Methode"). Zbl. Chir. 52: 1534-1537 (1925).

3. Miller, J. B., Conyers, W. H., Jr., \& Dinhoffer, N. A| Simple, Safe Bronchographic Technique for Children. J. Pediat. 96: 721-727 (1950).

4. Parkhouse, J. Bronchography under Ether. Brit. J. Anaesth. 29: 447-465 (1957):

5. Smith, R. M. Anesthesia for Infants and Children. St. Louis: C.V. Mosby (1959).

6. Bowering, M. W. An Aid to General Anaesthesia for Bronchograms. Canad. Anaesth. Soc. J. 6: 283-284 (1959).

7. KInCAID, O. W. The Problem of Repeated Exposure to Radiation by Anesthesiologists. Anesth. and Analg. 37: 316-370 (1958).

8. X-Ray Protection, Handbook 60, National Bureau of Standards, U.S. Department of Commerce (Dec. 1955).

9. BAKER, A. H. L. Endobronchial Lipiodol under General Anaesthesia in Children. Brit. J. Anaesth. 17: 112-116 (1941).

10. Leigh, M. D., \& Belton, M. K. Pediatric Anaesthesia. New York: Macmillan (1948).

11. Fortin, G., \& Tremblay, L. Can. Anaesth. Soc. J. 6: 289-290 (1959).

12. Fink, B. R. A Nonrebreathing Valve of New Design. Anesthesiology 15: 471-474 (1954).

13. Ruben, H. Combination Resuscitator and Aspirator. Anesthesiology 19: 408-409 (1958).

14. Ayre, P. Anaesthesia for Hare-lip and Cleft Palate Operations on Babies. Brit. J. Surg. 25: 131-132 (1937).

15. Mackay, A., Trépanier, A., \& Dufresne, M. R. Selective Segmental Bronchography. J.A.M.A. 166: 1155-1158 (1958).

16. Metras, H. Une Sonde pour le cathétérisme des bronches du lobe supérieur| Presse méd. 55: 198 (1947).

17. Nordenström,-B. Bronchography by the Aspiration of Contrast Media. Acta Radiol. 44: 281-288 (Oct., 1955).

18. Mackay, A., \& Brodeur, P. Bronchographie avec le dionosil. Union Méd. Canad. 82: 781-790 (July, 1953). 